Louisiana State University

LSU Digital Commons

Faculty Publications

Department of Biological Sciences

4-1-2016

\title{
14th congress of combustion by-products and their health effects-origin, fate, and health effects of combustion-related air pollutants in the coming era of bio-based energy sources
}

\author{
Eva Weidemann \\ Umeå Universitet \\ Patrik L. Andersson \\ Umeå Universitet \\ Terry Bidleman \\ Umeå Universitet \\ Christoffer Boman \\ Umeå Universitet \\ Danielle J. Carlin \\ National Institute of Environmental Health Sciences (NIEHS)
}

See next page for additional authors

Follow this and additional works at: https://digitalcommons.Isu.edu/biosci_pubs

\section{Recommended Citation}

Weidemann, E., Andersson, P., Bidleman, T., Boman, C., Carlin, D., Collina, E., Cormier, S., Gouveia-Figueira, S., Gullett, B., Johansson, C., Lucas, D., Lundin, L., Lundstedt, S., Marklund, S., Nording, M., Ortuño, N., Sallam, A., Schmidt, F., \& Jansson, S. (2016). 14th congress of combustion by-products and their health effects-origin, fate, and health effects of combustion-related air pollutants in the coming era of biobased energy sources. Environmental Science and Pollution Research, 23 (8), 8141-8159. https://doi.org/ $10.1007 /$ s11356-016-6308-y

This Article is brought to you for free and open access by the Department of Biological Sciences at LSU Digital Commons. It has been accepted for inclusion in Faculty Publications by an authorized administrator of LSU Digital Commons. For more information, please contact ir@lsu.edu. 


\section{Authors}

Eva Weidemann, Patrik L. Andersson, Terry Bidleman, Christoffer Boman, Danielle J. Carlin, Elena Collina, Stephania A. Cormier, Sandra C. Gouveia-Figueira, Brian K. Gullett, Christer Johansson, Donald Lucas, Lisa Lundin, Staffan Lundstedt, Stellan Marklund, Malin L. Nording, Nuria Ortuño, Asmaa A. Sallam, Florian M. Schmidt, and Stina Jansson 


\section{Combustion By-Products and Their Health Effects - Origin, fate, and health effects of combustion-related air pollu- tants in the coming era of bio-based energy sources.}

\section{A summary of the $14^{\text {th }}$ Congress - Umeå, Sweden.}

Eva Weidemann ${ }^{\mathrm{a}}$,Patrik L. Andersson ${ }^{\mathrm{a}}$, Terry Bidleman ${ }^{\mathrm{a}}$, Christoffer Boman ${ }^{\mathrm{b}}$, Danielle J. Carlin ${ }^{\mathrm{c}}$, Elena Collina ${ }^{\mathrm{d}}$, Stephania A. Cormier ${ }^{\mathrm{e}}$, Sandra C. Gouveia-Figueira ${ }^{\mathrm{a}}$, Brian K. Gullett ${ }^{\mathrm{f}}$, Christer Johansson ${ }^{\mathrm{g}}$, Donald Lucas ${ }^{\mathrm{h}}$, Lisa Lundin ${ }^{\mathrm{a}}$, Staffan Lundstedt $^{\mathrm{a}}$, Stellan Marklund ${ }^{\mathrm{i}}$, Malin L. Nording ${ }^{\mathrm{a}}$, Nuria Ortuño ${ }^{\mathrm{j}}$, Asmaa A Sallam $^{\mathrm{e}}$, Florian M. Schmidt ${ }^{\mathrm{b}}$, Stina Jansson ${ }^{\mathrm{a}, *}$

a Department of Chemistry, Umeå University, SE-90187 Umeå, Sweden

${ }^{\mathrm{b}}$ Thermochemical Energy Conversion Laboratory, Department of applied Physics and Electronics, Umeå University, SE-901 87 Umeå, Sweden

${ }^{c}$ National Institute of Environmental Health Sciences, National Institutes of Health, Department of Health and Human Services, Research Triangle Park, North Carolina 27711, USA.

${ }^{\mathrm{d}}$ Department of Earth and Environmental Sciences, University of Milano-Bicocca, Piazza della Scienza 2, Milano, 20126, Italy

e Department of Pediatrics, University of Tennessee Health Science Center, 50 North Dunlap Street, Memphis, Tennessee, 38103, USA and Children's Foundation Research Institute, Le Bonheur Children's Hospital, Memphis, Tennessee, USA

${ }^{\mathrm{f}}$ U.S. Environmental Protection Agency, Office of Research and Development, National Risk Management Research Laboratory, Research Triangle Park, North Carolina 27709, USA

g Department of Environmental Science and Analytical Chemistry, Stockholm University, SE-106 91 Stockholm, Sweden (also at the Environment and Health Administration, Stockholm, Sweden)

${ }^{\mathrm{h}}$ Lawrence Berkeley National Laboratory, University of California, Berkeley, Berkeley, California 94720, USA

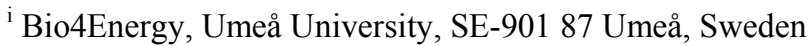

${ }^{j}$ Chemical Engineering Department, University of Alicante, P.O. Box 99, 03080 Alicante, Spain

Keywords: products of incomplete combustion, human health, soot, particles, polychlorinated dibenzo-p-dioxins, polychlorinated dibenzofurans, Congress paper

ABSTRACT: The $14^{\text {th }}$ International Congress on Combustion By-Products and Their Health Effects was held in Umeå, Sweden from June $14^{\text {th }}$ to $17^{\text {th }}$, 2015. The Congress, mainly sponsored by the National Institute of Environmental Health Sciences Superfund Research Program and the Swedish Research Council for Environment, Agricultural Sciences and Spatial Planning, focused on the 'Origin, fate and health effects of combustion-related air pollutants in the coming era of biobased energy sources'. The international delegates included academic and government researchers, engineers, scientists, policymakers and representatives of industrial partners. The Congress provided a unique forum for the discussion of scientific advances in this research area since it addressed in combination the health-related issues and the environmental implications of combustion by-products. The scientific outcomes of the Congress included the consensus opinions that (a) there is a correlation between human exposure to particulate matter and increased cardiac and respiratory morbidity and mortality; (b) because currently available data do not support the assessment of differences in health outcomes between biomass smoke and other particulates in outdoor air the potential human health and environmental impacts of emerging air pollution sources must be addressed. Assessment will require the development of new approaches to characterize combustion emissions through advanced sampling and analytical methods. The Congress also concluded the need for better and more sustainable ewaste management and improved policies, usage and disposal methods for materials containing flame retardants.

\section{Abbreviations}

quantitative structure-activity relationships QSAR

polybrominated dibenzo-p-dioxins and dibenzofurans (PBDDs and PBDFs) 
polybrominated diphenyl ether (PBDE)

brominated flame retardants (BFRs)

polychlorinated dibenzo-p-dioxins and dibenzofurans (PCDDs and PCDFs)

polychlorinated naphthalenes (PCNs)

organic carbon to elemental carbon $(\mathrm{OC} / \mathrm{EC}$

aryl hydrocarbon $(\mathrm{AhR})$ receptor

transthyretin (TTR

polycyclic aromatic hydrocarbons (PAHs)

polychlorinated biphenyls (PCBs)

persistent organic pollutants (POPs

\section{Introduction}

The International Congress on Combustion By-Products and Their Health Effects is a well-established platform for chemists, engineers and biomedical researchers to discuss current scientific issues related to combustion and combustion-associated human health impacts. The first Congress was held in 1989 at the University of California, Los Angeles, USA. Following the success of that meeting, the Congress was established, initially annually and later as a biennial event at locations that alternated between the USA and other countries (Dellinger et al. 2008, Lomnicki et al. 2014). The 14th Congress was recently held in Umeå, Sweden from June 14th to 17th, 2015, with the primary theme of 'Origin, fate, and health effects of combustion-related air pollutants in the coming era of bio-based energy sources'.

The Congress is unique in that it brings together very diverse participants to discuss and address emerging issues associated with combustion. The primary aim of the Congress is to maximize constructive scientific engagement between stakeholders in order to advance knowledge in the fields of environmental health and engineering sciences in relation to combustion. Combustion is addressed in its broadest sense, including all forms of thermal reactions that may occur either accidentally or intentionally, such as catalytic oxidation, thermal desorption processes, pyrolytic reactions and incineration. The Congress includes investigations of the sources and health effects of toxic by-products from thermal reactions, for example energy production and biomass burning. Although participants view these issues from different perspectives they share common goals to minimize combustion-derived pollution and to address its human health impacts.

Combustion-derived pollutants are recognized to exert significant environmental and human health effects. Two examples are polychlorinated dibenzo- $p$-dioxins/dibenzofurans and particulate matter, which are generated by complex chemical and physical processes during combustion. Despite many research efforts, the precise mechanisms of formation, potential emissions from new sources and overall epidemiological impacts of both classes of pollutant remain to be fully understood. It is hoped that the interaction of researchers from complementary scientific disciplines will encourage further research and improved understanding of such mechanisms and their effects. This year's Congress comprised eleven sessions organized around common themes, as illustrated in Figure 1.

Presentations by international experts in the fields of environmental science, chemistry, engineering and biomedical research provided learning opportunities for all delegates. Poster sessions, knowledge exchange events and an emphasis on active participation by early career researchers created numerous training and development opportunities for students and postdoctoral research fellows. During this year's Congress, trainees and junior faculty members gave presentations in all sessions and student awards were granted for best oral and poster presentations. Associate Professor Kees Olie (University of Amsterdam) was the winner of the prestigious Adel Sarofim Award for his extensive contributions to environmental pollution research. The award was presented in honor of Professor Adel Sarofim, who was a leader in combustion research and the driving force behind establishing the Congress. 


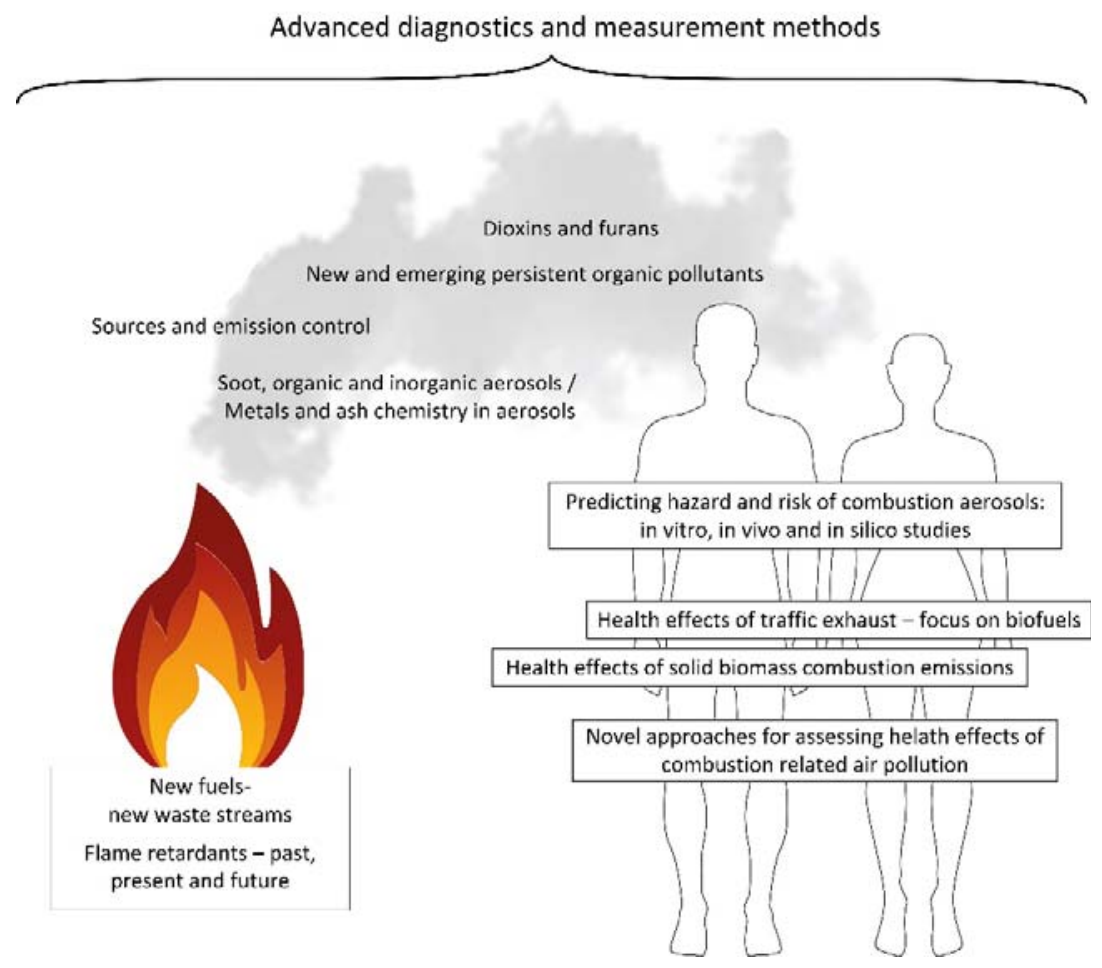

Figure 1. An illustration of the common themes connecting the sessions and topics discussed during the $14^{\text {th }}$ Congress.

Plenary presentations

Each day of the congress commenced with an invited plenary presentation by a leading expert in a major field that was the primary subject, reinforcing the overall themes of the Congress.

The first day of the congress commenced with a lecture by Professor Bogdan Dlugogorski, (Murdoch University, Australia), who summarized current knowledge about the mechanisms of formation of chlorinated, brominated and mixed, halogenated dibenzo-p-dioxins and dibenzofurans. Bench-scale combustion systems, sophisticated analytical chemistry techniques, accurate quantum chemical calculations and large scale experiments have been used to probe within the chemical complexity of combustion and to describe a comprehensive framework of mechanisms for the formation of halogenated pollutants during fires and incineration processes. In particular, the formation of polychlorinated dibenzo-p-dioxins and dibenzofurans (PCDDs and PCDFs) has been extensively studied and recent research, in which halogenation profiles were experimentally determined to be correlated to predictions based on Fukui function calculations, has demonstrated that electrophilic substitution is a major chlorination mechanism. Other studies have demonstrated the formation of intermediate bicyclic and tricyclic aromatic structures by the fusing of small carbonaceous species and by the disintegration of more complex carbon-containing structures. While the mechanisms relating to homogeneous gas phase formation of halogenated dibenzo-p-dioxins and dibenzofurans are now well understood their heterogeneous formation, especially the de novo synthesis of mixed halogenated dibenzo-p-dioxins and dibenzofurans, requires further investigation.

Experimental studies of brominated dibenzo-p-dioxins and dibenzofurans (PBDDs and PBDFs) have established inventories of their emission sources and have documented their significantly high formation rates during the decomposition of brominated flame retardants (BFRs). Incomplete decomposition of BFRs results in the precursor-mediated formation of PBDDs and PBDFs, while complete BFR destruction promotes their formation via de novo synthesis. The co-combustion of BFRs with a chemical source of chlorine results in the formation of mixed brominated and chlorinated dibenzo-p-dioxins and dibenzofurans. Formation of PBDDs and PBDFs in industrial processes is less predictable than the formation of PCDDs and PCDFs, which suggests more diverse mechanisms of formation. In both homogeneous and heterogeneous pathways of PBDD and PBDF formation, bromine has been demonstrated to originate mainly from organic bromine. As for the chlorinated dibenzo-p-dioxins and dibenzofurans, high levels of metals in e-waste appear to exert significant catalytic effects in the de novo formation of brominated dibenzo-p-dioxins and dibenzofurans. Because knowledge gaps remain, more definitive experimental studies are needed to explore and understand the formation of mixed halogenated dibenzo- $p$-dioxins and dibenzofurans from contaminated fuels during energy recovery. 
The second day of the congress was opened by Professor Angela Violi (University of Michigan, USA) who demonstrated the application of molecular dynamics simulation to characterize interactions between combustion-related nanoparticles and cell surfaces. Worldwide epidemiological studies have shown that human exposure to respirable particulate matter is correlated with increases in cardiac and respiratory morbidity and mortality. Without question, combustion is a major source through which particulate matter enters the atmosphere and it is therefore important to understand the characteristics of these particles and their relation to adverse health effects. In addition to environmental exposure through combustion-generated nanoparticles, another human exposure route is the intentional use of nanoparticles in engineering applications. The increasing use of manmade nanomaterials to improve the performance of consumer products and medical treatments may significantly increase the potential for human occupational and environmental exposure to nanoparticles. Only recently have the potential health impacts of such exposure been critically questioned.

Using molecular dynamics simulations, Violi's research has provided mechanistic insights at the molecular level into the relationships between nanoparticle morphology, composition and direct interactions with cell bilayers. Local structural changes due to nanoparticle-bilayer interactions at the atomistic level are currently being explored. She concluded that research should focus on the carbonaceous nanoparticles produced during combustion processes and on synthetic carbon-based nanoparticles to improve our understanding of their basic physical interactions at the nanoparticle-biological interface.

The third and final day of the congress was opened by Professor John Dyke (University of Southampton, UK), who presented research conducted by his group into understanding the significance of reactive chemical intermediates during combustion. Although intermediates are invariably present in a combustion environment at low concentrations and have short lifetimes, they strongly influence the formation of final products and the branching ratios between different product channels. The ratios of products from different reaction pathways depend upon the physico-chemical properties and chemical reactivity of intermediates. Ions are also produced in flames and the high level of non-equilibrium ionization found in any hydrocarbon flame can be traced to the chemi-ionization reaction $\mathrm{CH}+\mathrm{O} \rightarrow \mathrm{HCO}^{+}+\mathrm{e}^{-}$. In addition to these organic cations, metals and metallic compounds may also be present in flames because of their incorporation in the fuel used or their addition to modify combustion conditions. The presence of metals or metallic compounds modifies flame chemistry and enhances the ion abundance through further chemi-ionization reactions.

Examples were presented of studies conducted by the Southampton group which investigated different aspects of the chemistry of combustion, particularly to provide new information on reactive intermediates that are important in combustion processes.

\section{I: Studies of reactive intermediates by photoelectron spectroscopy}

Free radicals that are regularly observed in combustion processes include $\mathrm{CH}_{2} \mathrm{OH}$, $\mathrm{HCO}$, and $\mathrm{HO}_{2}$. For each radical the first adiabatic ionization energy was measured and the vibrational structure of the first photoelectron band was observed. The adiabatic ionization energy allows the heat of formation of the ion and other thermodynamic values to be determined.

\section{II: Investigation of ion production in chemi-ionization reactions}

Examples of chemi-ionization reactions were discussed, in which identification of the ions produced and measurement of their electron energy distributions enabled the establishment of reaction paths for ion production and the detailed investigation of mechanisms and energies of the associated chemi-ionization processes.

\section{III: Studies of the decomposition of potential fire extinguishants under controlled conditions}

For each fire extinguishant studied, decomposition pathways were identified and the routes of formation and depletion of reactive intermediates, such as $\mathrm{CF}_{2}$, were established.

Technical sessions

The $14^{\text {th }}$ Congress was organized into 11 technical sessions, of which 10 were conducted in two parallel programs (Figure 2). 


\begin{tabular}{|c|c|}
\hline \multicolumn{2}{|c|}{ Sunday June $14^{\text {th }}$ : Opening of the Conference } \\
\hline \multicolumn{2}{|c|}{ Monday June $15^{\text {th }}$} \\
\hline \multicolumn{2}{|c|}{ Plenary Speaker: Bogdan Z Dlugogorski } \\
\hline $\begin{array}{l}\text { New fuels - New waste streams } \\
\text { Session Keynote: Ignacio Aracil }\end{array}$ & $\begin{array}{l}\text { Predicting hazard and risk of combustion } \\
\text { aerosols: in vitro, in vivo and in silico studies } \\
\text { Session Keynote: Laura Van Winkle }\end{array}$ \\
\hline $\begin{array}{l}\text { Sources and emission control } \\
\text { Session Keynote: Jo Van Caneghem }\end{array}$ & $\begin{array}{c}\text { Novel approaches for assessing health effects } \\
\text { of combustion related air pollution } \\
\text { Session Keynote: Tim Nawrot }\end{array}$ \\
\hline \multicolumn{2}{|c|}{ Poster session } \\
\hline \multicolumn{2}{|c|}{ Tuesday June $16^{\text {th }}$} \\
\hline \multicolumn{2}{|c|}{ Plenary Speaker: Angela Violi } \\
\hline $\begin{array}{l}\text { Dioxins and furans } \\
\text { Session Keynote: Roland Weber }\end{array}$ & $\begin{array}{l}\text { Health effects of traffic exhaust } \\
\quad-\text { focus on biofuels } \\
\text { Session Keynote: Thomas Sandström }\end{array}$ \\
\hline $\begin{array}{l}\text { New and emerging } \\
\text { persistent organic pollutants } \\
\text { Session Keynote: Magnus Engwall }\end{array}$ & $\begin{array}{c}\text { Soot, organic and inorganic aerosols/ Metals } \\
\text { and ash chemistry in aerosols } \\
\text { Session Keynote: Joakim Pagels }\end{array}$ \\
\hline \multicolumn{2}{|c|}{$\begin{array}{l}\text { Advanced diagnostics and measurement methods } \\
\text { Session Keynote: Per-Erik Bengtsson }\end{array}$} \\
\hline \multicolumn{2}{|c|}{ Wednesday June $17^{\text {th }}$} \\
\hline \multicolumn{2}{|c|}{ Plenary Speaker: John Dyke } \\
\hline $\begin{array}{l}\text { Flame retardants } \\
\text { - past, present and future } \\
\text { Session Keynote: Ake Bergman }\end{array}$ & $\begin{array}{l}\text { Health effects of solid biomass } \\
\text { combustion emissions } \\
\text { Session Keynote: Torben Sigsgaard }\end{array}$ \\
\hline \multicolumn{2}{|c|}{ Closing remarks } \\
\hline
\end{tabular}

Figure 2. Technical program of the $14^{\text {th }}$ International Congress on Combustion By-Products and Their Health Effects

The research presented in the individual technical sessions is summarized and discussed below. In addition to the technical sessions, a poster session was also held which addressed the same subject areas.

\section{New fuels - New waste streams}

Ignacio Aracil (University of Alicante, Spain) opened the session by presenting an overview of the waste produced and treated within the European Union, with a focus on waste-to-energy treatment. Aracil discussed hazardous waste streams associated with the recycling of electrical and electronic equipment due to the presence of heavy metals, brominated flame retardants and other hazardous constituents. Thermal treatment provides an interesting alternative to recycle this kind of waste, but particular consideration must be given to potentially toxic emissions and by-products. For example, the incineration of polyvinyl chloride-coated electrical cables yielded very high PCDD and PCDF emissions. (Conesa et al. 2013). Similarly, the thermal processing of printed circuit boards, which represent around six percent of all e-waste by weight, is particularly problematic because of the heterogeneous combination of organic materials, metals and glass fiber (Ortuño et al. 2014). Studies have demonstrated that emissions of PCDDs and PCDFs were lower than emissions of PBDDs and PBDFs, probably due to the higher bromine content of printed circuit boards. Emissions data from the incineration or thermal decomposition of several problematic waste streams, such as end of life motor vehicles (Edo et al. 2013), wooden framed furniture (Moreno \&Font 2015), mattresses (Garrido \&Font 2015), marine debris and olive mill waste (Benavente \&Fullana 2015) were also presented and discussed.

Next, the influence of including food waste upon the combustion properties of municipal waste was addressed by Mar Edo Gimenez (Umeå University, Sweden) who described a study in which the influence of food waste content in mixed fuels, based on municipal solid waste and woody materials, affected combustion properties. The tested fuels were commercial 
softwood pellets, recovered wood, municipal solid waste (containing up to $20 \%$ food waste) and refuse-derived fuel with $5 \%$ and $20 \%$ food waste content. Simultaneous thermal analysis was used to evaluate the combustion behavior in terms of volatile matter content, ignition temperature, chlorine content, and released energy. Edo demonstrated that pure wood fuels presented higher volatile matter content, lower ash, sulfur and chlorine content and higher ignition point than the municipal solid waste and refuse derived fuels. Reducing the wood content of fuel blends corresponded to higher energy content - except for the municipal solid waste blends - lower ignition point and higher chlorine content. A fuel blend of wood mixed with $80 \%$ refuse-derived fuel and $5 \%$ food waste presented enhanced fuel properties compared to other fuel blends including reactivity, which facilitates ignition. The reduction of overall chlorine and sulfur content in the fuel blend with increasing wood content has implications for the potential formation of pollutants during waste incineration.

The following presentation by Lavrent Khachatryan (Louisiana State University, USA) included a kinetic modeling study of the fractional pyrolysis of lignin. Lignin is a promising plant material for the pyrolytic production of biofuels and renewable chemical feedstocks from bio-oils, which are pyrolysis liquids (Domínguez et al. 2008). The fractional pyrolysis of lignin was studied over the temperature range $200-900^{\circ} \mathrm{C}$ in a laboratory scale reactor. The major products of lignin pyrolysis at $400-450{ }^{\circ} \mathrm{C}$ were syringol, catechol, guaiacol, eugenol, phenol and related derivatives, whilst at 500-600 ${ }^{\circ} \mathrm{C}$ the major products of pyrolysis were the aromatic hydrocarbons toluene, benzene and styrene. A kinetic model, including primary and secondary reactions, was applied to the decomposition of lignin and the formation of pyrolysis products in bulk components (e.g. tar, gas, char). The calculated values agreed reasonable well with published experimental data (Jakab et al. 1995). Khachatryan observed that the fastest reaction was the decomposition of lignin and identified the significance of dehydrated lignin intermediates in the chemistry of lignin fractional pyrolysis for the first time. This modeling approach has been demonstrated to provide reasonably accurate estimation of the kinetics and yields of obtained products.

Jun Wang (Zhejiang University, P.R. China) investigated the possibility of producing hydrogen-enriched synthesis gas (syngas) from petroleum sludge by catalytic pyrolysis. In 2012 China produced more than 3 million tons of this hazardous waste, which contains significant amounts of valuable hydrocarbons. Three different sludge samples of $2 \mathrm{~g}$ weight were subjected to two-stage pyrolysis in a laboratory scale reactor with and without dolomite as catalyst. Most oil components volatilized in the first stage and underwent catalytic cracking in the second stage to form hydrogen, methane, carbon monoxide and other small gaseous molecules. The gas yield from non-catalytic pyrolysis was relatively low, but catalytic pyrolysis increased gas yields by one order of magnitude at $900-1000{ }^{\circ} \mathrm{C}$. The $\mathrm{H}_{2}$ volume fraction increased with increasing temperature and reached about $40 \%$ at $1000{ }^{\circ} \mathrm{C}$. The removal of solid particles from sludge samples by dissolution and centrifugation further enhanced syngas production and increased the hydrogen volume fraction to about $70 \%$. Wang concluded that this relatively simple process provides an efficient method for the conversion of petroleum sludge into a suitable feedstock for hydrogen production.

To conclude the session, Qiuju Gao (Umeå University, Sweden) presented a study of the formation of PCDDs, PCDFs and polychlorinated naphthalenes (PCNs) in solid, liquid, and gaseous products generated during the microwave-assisted pyrolysis of woody biomass. Gao conducted laboratory scale microwave-assisted pyrolysis experiments using commercial softwood pellets, bark pellets and chipped impregnated wood as feedstocks. During pyrolysis, non-condensable gas, aqueous phase, oil and chars were collected and analyzed for PCDDs, PCDFs and PCNs. All three classes were most abundant in the oil and the highest concentrations were formed from the pyrolysis of bark pellets, which has a relatively high content of chlorine and mineral matter. The second highest levels were formed by the pyrolysis of impregnated wood, which contains high levels of metal-based preservatives. Homologue profiles were dominated by the least chlorinated homologues and did not differ significantly between the three investigated feedstocks. The relatively high concentrations of PCDDs, PCDFs and PCNs generated by the pyrolysis of bark demonstrated the influence of feedstock composition on the formation of persistent organic pollutants. It was considered probable that the oxygen deficient conditions and relatively low temperatures of microwave-assisted pyrolysis, coupled with relatively homogeneous heating of the substrate, influenced the homologue profiles observed in the products.

\section{Predicting hazard and risk of combustion aerosols: in vitro, in vivo and in silico studies}

The keynote presentation for this session by Laura Van Winkle (University of California, USA) provided a broad overview of the health issues associated with fine and ultrafine particulate matter and specific emphasis upon the effects in children. She discussed the impacts of ultrafine inhalable particulate matter on lung development and the hypothesis that polycyclic aromatic hydrocarbons present in ultrafine particles with a high proportion of organic carbon to elemental carbon (OC/EC) will disproportionately affect neonatal animals, changing their airway growth and causing toxicity due to oxidative stress. Van Winkle presented results of effects after exposing 7-day-old neonatal and adult rats to a single 6-h exposure of fuel-rich ultrafine premixed flame particles, fine diffusion flame particles with different OC/EC ratios and filtered air. Ultrafine premixed flame particles with high OC/EC had greater effects in the lung than fine carbonaceous particles. Pulmonary cytotoxicity, gene expression and protein expression were evaluated at 2 and 24 hours after exposure. To investigate the mechanism 
of action of the ultrafine particles, the oxidative potential of the premixed flame particles and ambient particulate matter were measured and were found to be comparable. Since neonates are known to be more susceptible to the impacts of toxic exposure on airway growth than adults, Van Winkle concluded that i) ultrafine polycyclic hydrocarbon-rich particles induce compartmentalized cellular toxicity that is specific to the parenchymal/alveolar region in neonates, ii) ultrafine premixed flame particles activate the aryl hydrocarbon receptor (AhR) and the AhR-XRE pathway, upregulating CYP1A1 regardless of age but this response is delayed in neonates, iii) Neonates undergo oxidative stress, but fail to upregulate antioxidant enzymes thoroughly, iv) Neonatal glutathione and glutathione disulfide levels reduce precipitously following exposure, and the gamma glutamyl (glutathione regeneration) cycle is not upregulated post exposure in neonates.

The session continued with the presentation by Henning Bockhorn (Kahrlsruhe Institute of Technology, Germany) of a system for the prediction of human lung carcinogenic and other toxicological effects of diesel soot and synthetic carbon particles. The multi-stage evaluation system includes a human lung epithelial cell line (in vitro model), ex vivo tissue culture models and an in vivo rat inhalation model. The system uses well-characterized carbon black nanoparticles, carbon black nanoparticles modified by coating with benzo[a]pyrene or 9-nitroanthracene and carbon particles synthesized from acetylene and coated with substituted polycyclic aromatic hydrocarbons. When comparing the cytotoxic responses of healthy lung tissue and lung tissue in which emphysema was induced, no difference in response was observed after acute exposure to carbon black nanoparticles. However, carbon black nanoparticles treated with a surface coating of polycyclic aromatic hydrocarbons elicited increased toxicological responses and epithelial cell damage, even at low concentrations. Carbon black nanoparticles synthesized from acetylene were found to generate high levels of reactive oxygen species and to decrease transepithelial electrical resistance. From the in vivo inhalation studies it was deduced that a single oropharyngeal aspiration of surface modified carbon-black nanoparticles induced only minor lung alterations. Bockhorn concluded by stating that the observed differences in biological response to carbon black nanoparticles depend both on the lung compartment studied and the chemical nature of the nanoparticle surface.

Asmaa Sallam (University of Tennessee Health Science Center, USA) addressed the age-and tissue-specific disruption of Ecadherin mediated adhesion, which activates the $\beta$-catenin signaling pathway in neonatal dendritic cells as a result of exposure to particulate matter. It is well known that infants are susceptible to the effects of elevated levels of combustiongenerated particulate air pollution. For example, epidemiological studies have correlated high airborne particulate matter levels with increased infant hospital admissions with severe respiratory viral infections. Previous studies have demonstrated that the exposure of neonatal mice to combustion-derived particulate matter induces a tolerogenic immunophenotype. This phenotype correlated with disruption of the E-cadherin-mediated integrity of the airway epithelium and increased airway permeability. The interaction between airway epithelium and neonatal dendritic cells is critical to the fate and function of neonatal dendritic cells and consequently the ensuing immune response. An in vitro co-culture model was used to study the effects of particulate matter on interaction between the epithelium and neonatal dendritic cells, subsequent maturation of neonatal dendritic cells and the active accumulation of $\beta$-catenin. Sallam showed that exposure to particulate matter disrupts E-cadherin-mediated adhesion, which leads to functional activation of the $\beta$-catenin signaling pathway. In summary, the in vitro co-culture model has been demonstrated to be a promising research tool for the evaluation of age-and tissue-specific effects of exposure to particulate matter.

The final presenter of the session, Patrik Andersson (Umeå University, Sweden), discussed a range of in silico tools for the prediction of endocrine disrupting substances, including quantitative structure-activity relationships (QSARs) and protein binding affinities. Dr Andersson's research is currently directed towards chemicals that interfere with the thyroid hormone system, especially the thyroid hormone transport protein transthyretin (TTR) and the thyroid hormone receptor. A database of organic chemicals found in household dust has been compiled and is used with QSAR classification to screen substances that may potentially bind to TTR. Dr Andersson and his research team have identified a number of substances that bind to TTR, including the UV-filter 2,2',4,4'-tetrahydroxybenzophenone (UV 246) and perfluoroheptanesulfonic acid, which were further studied using protein interaction models to explore their mechanisms of action. In addition, metabolites of the indoor dust chemicals were proposed using in silico metabolic simulation and a number of these metabolites were also indicated to potentially bind to TTR, demonstrating the contribution of bio-activation to thyroid hormone disrupting substances. The results of Andersson's research suggest that in silico models can be applied to screen many classes of organic substances for potential endocrine disruption.

\section{Sources and emission control}

The session was opened by Jo Van Caneghem (Katholieke Universiteit Leuven, Belgium), who in her keynote presentation discussed data from three studies of the emissions of polycyclic aromatic hydrocarbons (PAHs) and polychlorinated biphenyls (PCBs) during incineration of three waste fuels (refuse-derived fuel, automotive shredder residue and waste water treatment sludge) in a fluidized bed combustor (Van Caneghem et al. 2014, Van Caneghem \&Vandecasteele 2014). The 16 U.S. EPA priority PAHs and the 12 dioxin-like PCBs were measured in the input waste and in all process outputs of a full scale 
fluidized bed combustor. Of the waste fuels, refuse-derived fuel and automotive shredder residue were the main sources of PAHs and phenanthrene, fluoranthene and pyrene were the most abundant PAHs measured. Naphthalene was the most abundant PAH in flue gas, which indicated its direct formation rather than transfer from the fuel. The profile of PAHs in the bottom ash corresponded closely to the PAH profile of the source fuel, indicating that it probably originated from unburnt fuel. Total PAH input/output ratios ranged from about $100 / 1$ to $2,600 / 1$, demonstrating that the fluidized bed combustor functioned as a net sink for PAHs. Van Caneghem also stated that commercial PCB oils were the major source of dioxin-like PCBs in the waste fuel inputs. The congener profiles of the flue gas and boiler/fly ash were significantly different from those of the input fuel, which indicated that dioxin-like PCBs in the input waste were destroyed during combustion and other dioxin-like PCBs were formed in the post-combustion zone. As for PAHs, the fluidized bed combustor functioned as a sink for PCBs.

In the following lecture, Brian Gullett (U.S.EPA, USA) presented research to establish emission factors from the open burning of biomass. He outlined the issues associated with wildfires, prescribed forest burning and agricultural fires which generate emissions that cause adverse human health effects, contribute to climate change and decrease visibility. Only limited data are available on the release of pollutants from these sources, particularly agricultural burns, due to the inherent difficulties and hazards in sampling their emissions. Airborne emissions were measured from prescribed forest burns of managed longleaf pine and grass/savanna and from agricultural burns of wheat stubble and Kentucky Blue Grass. Samples were collected to characterize the burn emission factors and to provide data for inclusion in plume dispersion models. Measurements were conducted by simultaneous aerial and ground sampling and the results were compared with measurements made in an open burn test facility to correlate field sampling and laboratory simulations. Gullett concluded that the development and application of a novel aerial sampling method enabled the measurement of emissions from a variety of sources for which lofted plumes, limited ground access and fire hazards constrain conventional, ground-based sampling (Aurell \&Gullett 2013).

Moo-Been Chang (National Central University, Taiwan) discussed the destruction of persistent organic pollutants (POPs) using catalytic oxidation of stack emissions. Catalytic filtration combines the functions of particulate filtration and catalytic destruction. Flue gas particles are collected on a filter membrane that prevents the particles from penetrating the catalytic felt substrate, thus minimizing catalyst fouling. Catalytic filtration has been successfully applied to remove PCDDs and PCDFs from gas streams of various thermal processes in Japan, Europe, and USA. In this study, a pilot-scale catalytic filter module was applied to remove PCDDs, PCDFs and their precursors from the flue gas of a large-scale municipal waste incinerator in Taiwan. The results presented by Chang showed that the removal efficiencies achieved with catalytic filtration were high (at an operating temperature of $180^{\circ} \mathrm{C}$ and filtration velocity of $1 \mathrm{~m} / \mathrm{min}$ ) and reduced the emissions of PCDDs and PCDFs below the legislative emission limit. The concentrations of pollutants measured in the fly ash collected in the pilot-scale catalytic filter module were significantly lower than those from conventional flue gas cleaning systems in Taiwan. However, significant formation of PAHs was still observed within the catalytic filtration system and further studies are needed to elucidate this phenomenon (Hung et al. 2014, Hung et al. 2011).

Moving down in scale from municipal solid waste incineration, Hanna-Lii Kupri (Estonian Environmental Research Centre and Tallinn University of Technology, Estonia) described her research into emissions from wood and household waste combustion in household stoves. Very limited information is available on the pollutant profiles of emissions from small scale combustion systems in which municipal solid waste is co-combusted with biomass. The co-combustion of municipal solid waste with wood fuels in a household stove may generate increased particulate, PAHs and PCDDs and PCDFs emissions with consequent harmful effects on human health and contamination of the stove and chimney. Furthermore, the emission factors developed by the European Environment Agency currently consider only pure biomass combustion and are low when compared to the average emission factors reported in the present study. 18 municipal solid waste combustion experiments were carried out to evaluate the historical changes in emissions associated with the composition of municipal solid waste. Mixtures of municipal waste and hard wood were co-combusted and the emissions characterized. Kupri concluded her presentation by noting that good correlations were observed between the formation of dioxin-like compounds and the concentration of hydrogen chloride in the flue gas and that, in some of the experiments, the concentrations of dioxin-like compounds exceeded the limits assigned to emissions from waste incineration plants, which emphasized the potential significance of this diffuse emission source.

Closing the session, Mengmei Zhang (Zhejiang University, P.R. of China) reviewed recent studies of open combustion as a source of PCDDs and PCDFs. Open burning and fires appear to provide almost optimal conditions for the formation and emission of products of incomplete combustion that include PCDDs and PCDFs. An extensive literature survey was performed on the subject of open burning to collect and collate data on PCDDs and PCDFs emissions from various sources, with special emphasis on the emission of PCDDs and PCDFs during the open incineration of polyvinyl chloride and brominated flame retardants. The concentrations of PCDDs and PCDFs in the combustion gases, their toxic equivalents and emis- 
sion factors (expressed as mass of pollutant per unit mass or volume of fuel) were compared for different source classifications. Zhang discussed the formation pathways of brominated and mixed halogenated dibenzo-p-dioxins and dibenzofurans from brominated flame retardants and also reviewed the influence of chlorine concentration on PCDDs and PCDFs formation, chlorination/bromination and halogen exchange reactions upon the final distribution of bromination, chlorination and mixed halogenation (Zhang et al. 2015).

\section{Novel approaches for assessing health effects of combustion related air pollution}

Tim Nawrot (Hasselt University, Belgium) began the session by introducing novel approaches to assess health effects of maternal exposure to combustion-related air pollution. Maternal nutrition and exposure to airborne chemical pollutants are some of the risk factors that contribute to age-related health conditions (cardiovascular, neurological) in adulthood. Mitochondria are involved in a variety of critical cell functions, including oxidative energy production and programmed cell death. Nawrot discussed how placental mitochondrial DNA can be used as markers for environmental stressors in early life and he presented evidence from the ENVIRONAGE (a research program linking ageing and environmental factors) birth cohort showing a negative association between placental mitochondrial DNA content and in utero exposure to particulate air pollution. In addition, he discussed how telomere length might reflect cumulative air pollution-induced damage as part of a core axis of biological ageing. Telomere length is highly heritable and telomere erosion leads to increasingly vulnerable structural integrity of the chromosomes. In a previous study, Nawrot's group showed that maternal residence proximity to a major road was associated with placental telomere length: a doubling in the distance to the nearest major road was associated with a $5.32 \%$ longer placental telomere length at birth. Recent evidence suggests that the placenta may influence central nervous system development through adaptive responses to the maternal environment in addition to its role in the transport of maternal nutrients, growth factors and hormones.

Danielle Carlin (National Institute of Environmental Health Sciences, USA) continued by presenting an overview of the wide range of research relating to combustion by-products that is supported by the National Institute of Environmental Health Sciences (NIEHS). The NIEHS supports these projects through regular and specialized funding programs such as the Superfund Research Program (Sciences 2015). The Superfund Research Program supports research related to combustion byproducts that is focused on problem-based/solution oriented, collaborative, and integrative sciences to understand not only the nature and source of exposure but also to understand the health impacts of such exposures and to translate this information into preventative action. The NIEHS recognizes that combustion by-products are significant sources of human exposure both in the US and around the world. Research into combustion-related exposure complements the strategic plan (U.S. Department of Health and Human Services 2012), which includes a global environmental health initiative and a strong focus on understanding and addressing health disparities (Figure 3). 


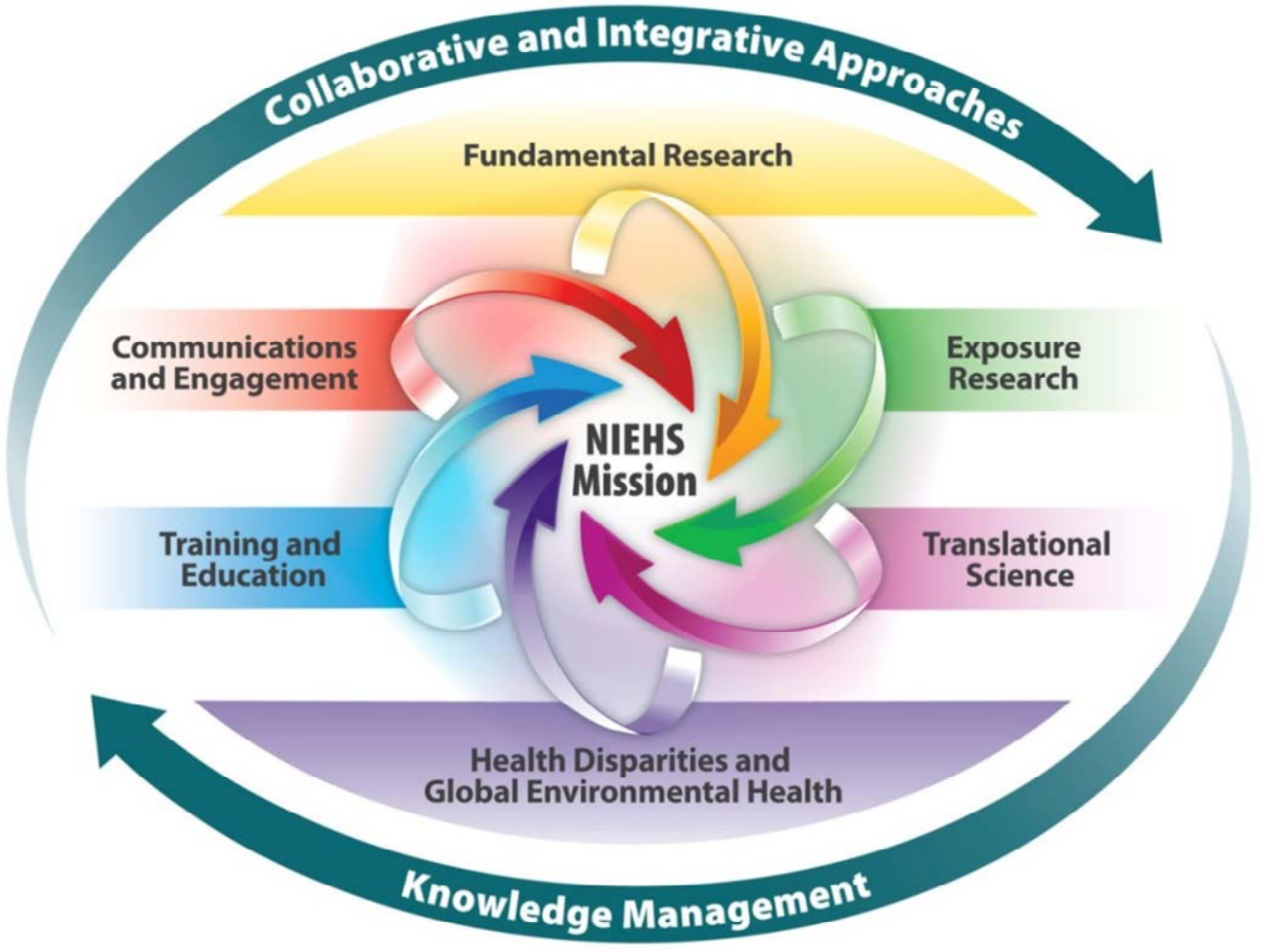

Figure 3. National Institute of Environmental Health Sciences mission

The session continued by addressing the respiratory effects of exposure to elevated levels of particulate matter, which has been associated with increased frequency and severity of lower respiratory tract infections (Vandini et al. 2013). Currently there is a critical gap in scientific understanding of how such exposure causes infection of the lower respiratory tract. Sridhar Jaligama, (University of Tennessee Health Science Center, USA) recently published data demonstrating that exposure during infancy to combustion derived particulate matter containing environmentally persistent free radicals not only damages respiratory epithelium but also induces immunosuppression (Lee et al. 2014). Current research presented by Stephania A. Cormier (University of Tennessee Health Science Center, USA) focused on understanding the mechanism of such immunosuppression. In particular, pulmonary $\mathrm{T}$ regulatory cells were shown to be implicated in this form of immunosuppression (i.e. suppression of protective type I CD4+ and CD8+ T cell responses) using depletion and adoptive transfer experiments. Further studies showed that the adaptive response was modulated by interleukin 10 and that if interleukin 10 was neutralized, protection against influenza was restored (manuscript in preparation).

Continuing on the topic of in utero exposure, Dries S. Martens (Hasselt University, Belgium) presented current research on changes to the neonatal cord blood lipidome that were associated with maternal exposure to particulate matter during pregnancy. The stage of in utero gestation is a critical window of susceptibility such that, if exposure takes place during this period, biochemical changes may occur that trigger diseases later in life. Martens is specifically interested in oxylipins, which are bioactive lipid compounds originating from the oxidation of different fatty acids, and the potential effects on their profiles in cord blood of in utero exposure to particulate air pollution. Martens' group has demonstrated that exposure to particulate matter $(2.5 \mu \mathrm{m})$ during pregnancy was correlated to changes in the production of four metabolites, representing the 5lipoxygenase pathway. These changes were positively associated with differences in maternal exposure during the second trimester and entire length of pregnancy. Eleven metabolites combined in a single Principal Component representing the 15lipoxygenase pathway were also positively associated with particulate matter exposure during the second trimester. No associations were found for the cyclooxygenase and cytochrome P450 pathways. These changes at the level of the lipidome indicated an altered inflammatory state of the newborn at birth which was induced by air pollution.

In the final presentation of the session, Hans Orru (Umeå University, Sweden and University of Tartu, Estonia) explained how his research group estimated the balance between the expected health benefits to the general population of Stockholm, Sweden, and the anticipated adverse health effects to users of a $21 \mathrm{~km}$ tunnel by-pass proposed to reduce traffic emissions in Stockholm, Sweden. Tunnel exposures to oxides of nitrogen $\left(\mathrm{NO}\right.$ and $\mathrm{NO}_{2}$ ) were estimated based on average levels, time 
spent in the tunnel, and the number of persons in the tunnel. The change in annual ambient concentrations of nitrogen oxides and particulate matter $(10 \mu \mathrm{m})$ were modeled to estimate an average exposure for residents of Stockholm. For the general population of Stockholm, a reduction of approximately 20 per cent in the number of premature deaths associated with exposure to oxides of nitrogen and particulate matter was estimated as a consequence of reduced ambient concentrations of nitrogen oxides and particulate matter $(10 \mu \mathrm{m})$ concentrations. However, a similarly proportionate increase in premature deaths associated with exposure to oxides of nitrogen and particulate matter was estimated for users of the new tunnel.

\section{Dioxins and furans}

Roland Weber (POPs Environmental Consulting, Germany) began the session by considering the increasing use of biomass in global energy production and the use of ashes from biomass combustion as fertilizers for agricultural and forestry soils. The risk of PCDDs and PCDFs contamination of soil from this practice is often not, or only partially, considered. The use of fuels other than wood increases the concentrations of PCDDs and PCDFs in the ash because some herbaceous biofuels have a higher chlorine content than wood. In addition, combustion of chemically treated waste wood can increase the formation and release of PCDDs and PCDFs by 10 to 100 times due to the high content of chlorine and/or metals that can act as catalysts. For example, in recent years a commercial "catalyst" (typically a copper salt) has been increasingly marketed in European countries to reduce the formation of soot in wood and coal stoves and has even been used in coal-fueled power plants. Compared to virgin wood, the use of this catalyst significantly increased the levels of PCDDs and PCDFs in the flue gas and in the ashes by a factor of 1,000 to 10,000 . The PCDDs and PCDFs content of the fly ash was greater than $15,000 \mathrm{ng}$ TEQ $\cdot \mathrm{g}^{-}$ ${ }^{1}$ ash, which exceeded persistent organic pollutants content limits set by the Basel Convention and requires the material to be considered as persistent organic pollutant waste. Weber concluded that the extremely high emissions of PCDDs and PCDFs associated with use of the catalyst create a pressing need to remove it from the market.

Continuing the subject of catalysis, Slawomir Lomnicki (Louisiana State University, USA) presented the results of his studies of the potential synergistic interaction between iron and copper as catalysts during the formation of PCDDs and PCDFs in combustion. He has evaluated the effects of fly ash surrogate systems containing both copper and iron oxides with varying ratios of $\mathrm{Fe}_{2} \mathrm{O}_{3}$ and $\mathrm{CuO}$ on a silica substrate $\left(4 \% \mathrm{Fe}_{2} \mathrm{O}_{3}: 1 \% \mathrm{CuO}, 2.5 \% \mathrm{Fe}_{2} \mathrm{O}_{3}: 2.5 \% \mathrm{CuO}\right.$ and $\left.1 \% \mathrm{Fe}_{2} \mathrm{O}_{3}: 4 \% \mathrm{CuO}\right)$ upon PCDDs and PCDFs formation at $200-550{ }^{\circ} \mathrm{C}$ under oxidative and pyrolytic conditions. Lomnicki concluded that under oxygen-rich combustion conditions the mixed oxide systems did not catalyze the formation of significant amounts of PCDDs and PCDFs, but under low oxygen, pyrolytic conditions (which are present in regions within incinerators) the presence of the mixed oxides on catalytic surfaces at moderate and high abundance can lead to high concentrations of PCDDs and PCDFs in emissions.

Sara Mosallanejad (University of Newcastle, Australia) continued on the subject of the role of iron and copper as catalysts for the formation of PCDDs and PCDFs in combustion systems and described her experimental investigation of the formation of volatile organic compounds and PCDDs and PCDFs by the oxidation of 2-chlorophenol on surfaces coated with $\mathrm{Fe}_{2} \mathrm{O}_{3} / \mathrm{SiO}_{2}$ in order to further understand the role of iron-rich fly ash on pollutant emissions from combustion systems. She confirmed the preferential formation of mono- to tri-CDDs and CDFs with 1-monoCDD, 1,6-diCDD, 1,9-diCDD and 4,6diCDF being the most abundant congeners. Phenol, 2,4-dichlorophenol, 2,6-dichlorophenol and 2,4,6-trichlorophenol are formed as a consequence of chlorination and dechlorination of 2-monochlorophenol. Dihydroxylation of the catalyst in combination with its chlorination and dechlorination capacity induce the formation of benzene, 1,3-, 1,4-, 1,2-dichlorobenzene, 1,2,4-, 1,3,5-, 1,2,3-trichlorobenzene and 1,2,3,5- and 1,2,3,4-tetrachlorobenzene. Dibenzofuran was not detected and the ratio of PCDDs to PCDFs was greater than one. The results indicated that Fe (III) and Cu (II) exert similar catalytic effects in the formation of PCDDs and PCDFs by precursor pathways.

Claudio Greco (University of Milano-Bicocca, Italy) discussed the potential formation of PCDDs and PCDFs from PAHs and the catalytic role of copper (I) oxide in the oxidative pathways of aromatic hydrocarbons. The catalytic site was modeled as a copper atom embedded in a silicate structure and reactions with molecular oxygen and benzene were investigated using Density Functional Theory. The results of Greco's theoretical assessment indicated that Cu can activate molecular oxygen to oxidise unsubstituted aromatic systems, because although the initial reaction of $\mathrm{O}_{2}$ with benzene has an activation energy of $37.3 \mathrm{kcal} \cdot \mathrm{mol}^{-1}$, evolution of the radical intermediate proceeds with a lower activation energy of $32.3 \mathrm{kcal} \cdot \mathrm{mol}^{-1}$ and the oxygenated aromatic radical species is significantly more stable than the reagents. However, experimental confirmation should be provided by characterizing the key intermediate species.

Nuria Ortuño (University of Alicante, Spain) concluded the session with a discussion of the long-term sampling of PBDDs and PBDFs and PAHs in the case study of a cement plant. A Dioxin Monitoring System ${ }^{\mathrm{TM}}$ was used for one year to assess the emissions of these pollutants in the stack gas from a cement plant under normal operating conditions. The plant, with a production capacity of $150 \mathrm{t} \cdot \mathrm{h}^{-1}$ of clinker, uses the co-incineration of different wastes to achieve a fuel substitution level of $40 \%$ in terms of energy. The analysis of ten samples showed that the total toxic PBDD and PBDF emissions ranged from 
0.01 to $0.44 \mathrm{pg}$ TEQ $\cdot \mathrm{Nm}^{-3}$ corresponding to $0.02-0.92 \mathrm{ngTEQ} \cdot \operatorname{ton}^{-1}$ clinker, with an estimated average emission factor of $2094 \mathrm{Nm}^{3} \cdot$ ton $^{-1}$ clinker. The analysis also revealed that the PBDD and PBDF congener patterns were similar for all samples, with octa-BDF as the most abundant congener and a PBDF/PBDD ratio greater than 1. From measurement of the 16 US EPA priority PAHs in three samples it was observed that naphthalene was the most abundant PAH while benzo(a)anthracene was the only carcinogenic PAH above the detection limit in one sample. Overall Ortuño noted that pollutant emission levels did not seem to be affected by the level of energy substitution using alternative fuels.

\section{Health effects of traffic exhaust - focus on biofuels}

Keynote speaker Thomas Sandström (Umeå University, Sweden) introduced this session by summarizing the extensive research by his group in the field of health effects of air pollution. The group has used human exposure chambers to investigate the effects of gaseous pollutants, motor engine exhaust and smoke/biomass combustion for decades, resulting in numerous scientific developments. The acute pro-inflammatory respiratory effects of diesel engine exhaust have been thoroughly described in their research and complemented with mechanistic research clarifying the upstream activation via the epidermal growth factor receptor tyrosine 1173 phosphorylation, as well as the downstream activation of mitogen-activated protein kinases, NF- $\mathrm{BB}$ activation and subsequent cytokine production. Sandström reported that for the particularly sensitive population of asthmatics, those using inhaled corticosteroid anti-inflammatory medication showed increased bronchial hyperresponsiveness upon exposure. Bronchoscopic examination has been conducted in several studies in order to assess bronchial immune responses and more recently it has been combined with cardiovascular assessment using bilateral underarm plethysmography. Applying the latter technique to volunteers after diesel engine exhaust exposure has provided evidence of disturbed vasomotor function, fibrinolysis and increased thrombocyte adhesion which can lead to impaired blood flow, increased risk of blood clotting and thrombosis. Sandström concluded his talk by highlighting the fact that biofuels are of increasing interest and of major importance as renewable fuels. However, the research on health effects from these fuels is still in its infancy. Throughout this session, scientific evidence presented by researchers increased the foundations and incentive for further health related research with regard to biofuels.

Jenny Bosson (Umeå University, Sweden) presented a summary of three separate studies in which healthy volunteers were exposed to petrodiesel exhaust, two types of biodiesel exhaust and filtered air as a control. All exposures were carried out for one hour in a randomized, double-blind crossover design. Cardiovascular endpoints, including vascular endothelial function and thrombus formation, and bronchoscopy outcomes (biopsies, bronchial wash and bronchoalveolar lavage) were assessed. Both petrodiesel and biodiesel exhaust exposures were found to cause similar thrombus formation and equivalent endothelial dysfunction. Bosson's study demonstrated that exposure to biodiesel exhaust results in comparable adverse respiratory and cardiovascular effects to petrodiesel exhaust, despite varying composition and particle reactivity.

The goal of the research presented by Masoumeh Karimpour (Umeå University, Sweden) was to investigate the effects of exposure to biodiesel exhaust on the human plasma metabolome (a combined array of circulating small-molecules and metabolites), and to compare the effects of exposure to petrodiesel exhaust. Healthy volunteers were exposed to either petrodiesel or biodiesel exhaust for one hour in a randomized, double-blind crossover study. Peripheral blood was sampled prior to exposure and at two, four, eight and 24 hours after exposure. Three metabolomics platforms were used for metabolite profiling and subsequent multivariate analysis identified metabolite profiles that were characteristic for each type of exposure. Furthermore, statistical analysis of the data revealed the time course of individual metabolite levels. Although the study is still in progress, it illustrates a novel approach to the investigation of health effects by assessing metabolite levels and profiles before and after biodiesel exhaust exposure.

Sandra Gouveia-Figueira (Umeå University, Sweden) described her study of unique bioactive lipids that are produced endogenously, including oxylipins, endocannabinoids and related compounds and which may be implicated in inflammatory diseases such as asthma. Plasma bioactive lipid profiles were compared in two separate studies of human volunteers exposed to biodiesel exhaust and 1) petrodiesel exhaust or 2) air, for one hour in a randomized, double-blind crossover study design. To detect alterations in bioactive lipids, highly sensitive ultra-performance liquid chromatography coupled to electrospray ionization tandem mass spectrometry analysis was used. The study demonstrated that circulating bioactive lipid profiles changed in response to exposure to diesel exhaust. Further studies are required to determine whether these bioactive lipids contribute to the increased incidence of inflammatory diseases such as asthma after exposure to air pollution.

To conclude the session, Arto Pennanen (National Institute for Health and Welfare, Finland) reported a study of the comparative impact on air quality of fossil and renewable diesel fuel in modern off-road vehicles in an underground mine. It has been established that diesel exhaust exposure is associated with an increase in lung cancer and it has been shown that alternative fuels, such as diesel mixed with hydrotreated vegetable oil, generates lower particulate matter and $\mathrm{NO}_{\mathrm{x}}$ emissions during combustion. Pennanen and colleagues performed a study within a large, well-ventilated underground mine in Finland with approximately 240 employees and an annual ore production of 1.3 million tons. The mining activities generate ambient die- 
sel exhaust from trucks, front loaders, vans and other machinery. In the study fossil diesel fuel was replaced with $100 \%$ hydrotreated vegetable oil for 6 days and measurements of particulate matter, $\mathrm{NO}_{\mathrm{x}}$ and other pollutants were made at various locations within the underground mine. Overall the use of hydrotreated vegetable oil resulted in the following findings. The average air quality in the mine was comparable to the worst hours of the year on busy streets in the city of Helsinki, whilst the general air quality improved slightly in comparison to fossil diesel use. Particulate matter $(2.5 \mu \mathrm{m})$ concentrations declined by around $13 \%$, black carbon concentrations by about $9 \%$, PAHs by around $15 \%$ and $\mathrm{NO}_{2}$ by approximately $22 \%$.

\section{New and emerging persistent organic pollutants}

Magnus Engwall (Örebro University, Sweden) opened this session discussing the application of mechanism-specific in vitro bioassays to the risk assessment of complex mixtures of PAHs from contaminated sites. Such contamination can be due to different classes of polycyclic aromatic compounds, such as non-substituted, substituted or heterocyclic hydrocarbons, as well as their mixtures. The US EPA's 16 priority PAHs are extensively used as an indication of the contamination level. Not only have these, but also a huge variety of different polycyclic aromatic compounds that are rarely studied and which may contribute to the toxicity of the samples. A more complete assessment of the toxicological potential of polycyclic aromatic compounds in biological systems can be achieved by using a combination of chemical analysis and mechanism-specific bioassays such as aryl hydrocarbon receptor based tests. Engwall stressed the advantages of this approach, including the generation of an integrated response based on the overall mechanism-specific effect of all chemicals present in the sample including any mixture interactions. Such assays are usually fast, sensitive, robust and cost-effective. An effect-directed approach to sample characterization that combines bioassay, physicochemical fractionation and chemical analysis was proposed as a powerful tool for comprehensive risk assessment. The results of chemical analysis are combined with congenerspecific relative potency factors and the assumption of concentration additivity to estimate the contribution of each analyte to effects observed in the bioassay.

On the subject of e-waste, Albert Leo N. de la Cruz (Louisiana State University, USA) presented data from the assessment of polybrominated diphenyl ether (PBDE) congeners in airborne particulate matter collected from an e-waste facility in Bangkok, Thailand. Waste electrical and electronic equipment is one of the fastest growing global waste streams and contains a number of priority pollutants including heavy metals, PCDDs, PCDFs, PCBs and brominated flame retardants in plastics. Thus, e-waste facilities can be a source of increased human exposure to such pollutants through ingestion (via the food chain), dermal exposure and inhalation but few studies have been conducted on emissions from e-waste processing. The results indicated that around 24 times higher concentrations of PBDEs were measured in particulate matter $(2.5 \mu \mathrm{m})$ than in total particulate matter and that the congener profiles were different between the two particle size fractions. An evaluation of exposure to PBDEs at an e-waste facility indicated that the estimated PBDE exposure was lower than the limit established by the U.S. EPA. De la Cruz also emphasized the potential significance of environmentally persistent free radicals formed from PBDEs via physisorption, chemisorption and electron transfer.

Cuicui Du (Zhejiang University, P.R. China) introduced a review of the catalytic oxidation of chlorinated aromatic compounds which are used extensively in the chemical and pharmaceutical industries. Current emission control techniques for these pollutants comprise phase transfer to adsorbents or absorbents, incineration, treatment by chemical, catalytic or microbiological methods and advanced photochemical and physicochemical techniques. The catalytic oxidation processes frequently combine noble metal catalysts with transition metal oxides and offer many advantages over other techniques, for example, the complete degradation of target pollutants, efficient operation at low temperatures and lower fuel costs. However, catalysts can become deactivated through fouling and become inefficient or generate unwanted by-products. Du also outlined the mechanisms of catalytic oxidation and shared results from applied research in the field of catalytic filtration.

Bogdan Z. Dlugogorski (Murdoch University, Australia) presented a research study performed by his student Song Hou (University of Newcastle, Australia) to investigate potential new pathways for the formation of toxic species during the thermal oxidation of 4-chlorobiphenyl in the temperature range $300-700{ }^{\circ} \mathrm{C}$ using laboratory scale laminar flow reactors. The influence of catalytic wall effects upon the chemical reactions was evaluated by using three different construction materials: 1) an alumina reactor, which exerted the highest catalytic effects, such as the promotion of singlet oxygen formation and chlorination/dechlorination activity at low temperatures; 2) a quartz tube reactor, which was associated with a lower rate of singlet oxygen formation and negligible chlorination/dechlorination activity; and 3) a quartz tube reactor that was surface passivated with a $\mathrm{B}_{2} \mathrm{O}_{3}$ coating upon which strictly gas-phase oxidation reactions should occur. The yields of 2-chlorophenol and 1-chlorobenzene indicated that the alumina and quartz reactors were surface-active, with lower onset temperatures for the formation of these compounds than the boron oxide passivated reactor. Although only mono-CDFs were detected at lower temperatures, various PCDD and PCDF isomers were formed above $550{ }^{\circ} \mathrm{C}$ in all reactors, with similar yields for all three reactors. Using Hou's results and quantum chemical calculations, an initiation pathway was proposed for the studied reactions and different potential mechanisms for the formation of PCDDs and PCDFs were presented. 
Closing the session, Roland Weber (POPs Environmental Consulting, Germany) reported on concentrations of PBDEs, PBDDs and PBDFs in the plastic components of e-waste exported to Nigeria and in related emissions from open burning of the e-waste. Several samples of polymer casings from cathode ray tubes were screened for brominated flame retardants using X-ray fluorescence, analyzed for octabrominated diphenyl ether, decabrominated diphenyl ether, tetrabromobisphenol A and 1,2-bis(2,4,6-tribromophenoxy)ethane and their PBDD and PBDF content was measured. The analyses revealed high levels of PBDDs and PBDFs, equating to an estimated content of 2 to 8 tonnes of PBDDs and PBDFs in waste cathode ray tube casings that have accumulated in Nigeria to date. Analogously, an estimated amount of 1270 tonnes of penta- and octa-BDE and around 10 times more deca-BDE could be present in the e-waste plastic imported to Nigeria. Since e-waste plastic is primarily processed by open burning in Nigeria, as confirmed in studies conducted by Weber and his co-authors at e-waste treatment sites in four different locations, this is potentially a major source of PBDE, PBDD and PBDF contamination.

\section{Soot, organic and inorganic aerosols / Metals and ash chemistry in aerosols}

Joakim Pagels (Lund University, Sweden) commenced the session with a keynote presentation on early research towards a conceptual model for the characterization of carbonaceous aerosol emissions. Emissions from small-scale wood combustion and vehicle engine exhausts are the focus of this research as they are two main sources of anthropogenic carbonaceous aerosols like soot (black carbon) and organic particulate matter. Recently, time-resolved in-situ techniques to investigate particle chemistry and microphysics have become available, for example aerosol particle mass analysis and tandem differential mobility-mass analysis can be applied to diluted particles directly from combustion sources. Pagels summarized recent studies conducted by his own group and others. In one example, crank angle resolved sampling of particles from a modern diesel engine showed that the oxidation rate rather than the soot formation rate controls engine soot emissions. Another study illustrated that, upon aging, diesel soot changed from being agglomerated and hydrophobic to collapsed soot cores with thick oxidized, hydrophilic coatings. The importance of the formation of secondary organic particles in the atmosphere was also addressed with examples given for gasoline engine exhaust. Furthermore, an interesting observation is that upon release to the atmosphere PAHs and other organic exhaust constituents are chemically degraded during both dark and UV aging, and in a recent study of wood smoke it was shown that this aging may also affect the toxicological properties of the aerosol particles. Pagels emphasized that detailed knowledge of different particle types and their properties is needed as well as clear understanding of the causes of their effects on health and climate. The application of new measurement techniques in combination with dedicated multidisciplinary research creates opportunities to gain novel insights about the formation of combustion aerosols and their impacts on human health, the atmosphere and the climate.

Antonis Christou (University of Central Lancashire, UK) described his study of the potential release of multi-wall carbon nanotubes from carbon nanotube polymer nanocomposite pellets during combustion at different temperatures. Multi-wall carbon nanotubes have attracted considerable interest from industries for novel applications related to their unique properties and may be used as alternative chlorine- and bromine-free fire retardant additives in polymers. However, there are concerns about potential inhalation exposure to pristine multi-wall carbon nanotubes, and limited information is available about their effects on the chemical and physical properties of aerosol emissions from treated polymers under combustion conditions. In this study, the potential release of multi-wall carbon nanotubes was investigated during the combustion of treated polymers. Polyamide 6.6 with different concentrations of multi-wall carbon nanotubes was burned at three temperatures $\left(400^{\circ} \mathrm{C}, 550^{\circ} \mathrm{C}\right.$ and $600^{\circ} \mathrm{C}$ ). The results of Raman spectroscopy and scanning electron microscopy analysis identified multi-wall carbon nanotubes in the ash residue from combustion at $550^{\circ} \mathrm{C}$, but not in the ash from combustion at $600^{\circ} \mathrm{C}$. However, catalytic metals were identified as a white residue in the ash from combustion at $600^{\circ} \mathrm{C}$. Christou also proposed a new approach to complement electron microscopy analysis for establishing the presence of multi-wall carbon nanotubes.

Hendryk Czech (Joint Mass Spectrometry Centre University of Rostock, Germany) presented research on organic emissions from residential wood combustion, which were characterized on-line using single-photon ionization time-of-flight mass spectrometry. This analytical technique, in which low ionization energy is applied to generate molecular ions for direct mass selective detection, can give novel time-resolved data on the abundances of volatile organic compounds in emissions from batch combustion of wood. Six consecutive batches of three common European types of log firewood (i.e. beech, birch and spruce) were burned in a modern wood-fired masonry heater. The temporal variation of volatile organic compounds was studied using the single-photon ionization time-of-flight mass spectrometry technique. In general, short-chain carbonyl compounds, alkenes and dienes, furan/isoprene and benzene (which are non-specific decomposition products) were present in the highest abundances, but phenolic species and anhydrous sugars (subunits of the wood polymers lignin and (hemi-)cellulose) were also observed. More than $50 \%$ of the overall abundances were observed during the combustion of the first two batches, in which mono- and polyunsaturated components with low $\mathrm{O} / \mathrm{C}$ ratio were predominant. In conclusion, using multivariate statistical analysis Czech demonstrated that phenolic species or anhydrous sugars were most abundant in emissions during 'stable combustion', whereas the 'ember' phase of combustion was characterized by unsaturated hydrocarbons and secondary decomposition products dominated the 'ignition' phase of combustion. 
Jennie Hurkmans (Stockholm University, Sweden) addressed the potential to differentiate carbonaceous aerosols by comparing the absorption of light at different wavelengths. A black carbon source apportionment study was conducted for the first time in Sweden to assess the contributions of fossil fuel and wood burning emissions to airborne black carbon using data from a multi-wavelength aethalometer. It was assumed that brown carbon is mainly associated with wood burning. Data from two urban sites in Stockholm, an urban street canyon and an urban background, were collected during a 20 month period. The results indicated that black carbon from wood burning contributed on average $34 \pm 6 \%$ and $16 \pm 6 \%$ to total black carbon in the urban background and the street canyon, respectively. The wood burning contribution showed a clear annual trend, increasing in winter and decreasing in summer. Highest contributions to particulate matter $(2.5 \mu \mathrm{m})$ were found for black carbon from fossil fuel during rush hour periods in the street canyon, reaching a maximum value of $17 \%$. Black carbon from wood burning contributed around $5 \%$ of total particulate matter $(2.5 \mu \mathrm{m})$ to the urban background during winter.

Elisabeth Feld (Louisiana State University, USA) completed the session with a presentation on the effects of metal speciation on environmentally persistent free radical formation in fly ash. Environmentally persistent free radicals are recently identified pollutants that exhibit extreme stability and persistence in environmental and biological environments. They form through series of surface-mediated reactions with chlorinated aromatic compounds on solid combustion by-products including particulate matter, fly ash and soot. Because environmentally persistent free radicals are implicated in the health effects of exposure to emitted particulates by triggering oxidative stress, it is important to discover factors that can suppress their formation. Feld demonstrated that making compositional changes (by the addition of calcium and sulfur) to fly ashes led to the suppression of environmentally persistent free radicals formation on fly ash particles. Five types of "surrogate particles" with different calcium and sulfur contents were used in addition to fly ash samples to assess the impact of compositional variability. The concentrations of metals $(\mathrm{Cu}, \mathrm{Fe}, \mathrm{Mg}, \mathrm{Mn}, \mathrm{Zn})$ were selected on the basis of known fly ash composition and the surrogate surfaces were characterized. The concentration and location (surface or bulk) of the metals, calcium and sulfur were elucidated. After characterization, the surrogate particles were exposed to 2-monochlorophenol and the concentration and type of environmentally persistent free radicals formed was compared.

\section{Advanced diagnostics and measurement methods}

The final session of the second day of the congress was opened by Per-Erik Bengtsson (Lund University, Sweden), who introduced the many applications of laser-based diagnostics for reactive flow systems. During the last decade, laser spectroscopic methods have undergone significant development and have led to a better understanding of the chemical reactions in combustion environments, such as in flames, internal combustion engines and industrial furnaces. Optical techniques based on incandescence, laser-induced fluorescence and light absorption are non-intrusive, offer high temporal and spatial resolution and enable multi-species, in situ measurements of atoms, molecules or particles in hot gases. Bengtsson's presentation introduced experimental applications of laser spectroscopic techniques with examples in which flow properties and species concentrations were visualized as a function of time in two or three dimensions. However, these techniques are current limited by the need for sophisticated equipment and their applicability to small molecules. Because the reduction of soot emission in incomplete combustion processes is important for environmental and health reasons, methods for the measurement of soot particles were discussed in detail. The most common optical techniques for detection of soot volume fractions and particle size distribution rely on thermal radiation, extinction, elastic light scattering and laser-induced incandescence. Bengtsson presented several examples to demonstrate that laser-based techniques can successfully be applied in laboratory flames as well as in larger-scale entrained flow gasifiers.

Ramin Ghorbani (Umeå University, Sweden) presented research on the detection of exhaled carbon monoxide using a compact mid-infrared laser absorption spectrometer. The aim of his research is to evaluate exhaled breath carbon monoxide as a biomarker of respiratory disease and inflammation in order to study the health effects of combustion by-products. Exhaled breath gas analysis is a novel approach for non-invasive medical diagnostics, disease monitoring, physiological studies and toxicology. In human exposure studies of air pollution health effects, breath gas analysis can complement established clinical methods which are often invasive and time-consuming. Partly originating from systemic heme oxygenase activity, exhaled breath carbon monoxide is one of the most promising biomarkers of oxidative stress and related diseases. The use of laser spectroscopy allows calibration-free, real-time monitoring of breath exhalation profiles and alveolar carbon monoxide concentrations with high sensitivity, selectivity and precision. Ghorbani presented initial measurements of exhaled breath carbon monoxide exhalation profiles of healthy non-smokers with alveolar $\mathrm{CO}$ concentrations of just below 1 ppmv. Increased knowledge of the biomarkers of oxidative stress and respiratory inflammation will facilitate improvements in the diagnosis and therapeutic monitoring of pulmonary diseases.

Mariana Ghosh (Southampton University, UK) presented a novel approach to study chemical reactions and free radicals in or near single particles under controlled environmental conditions. Large amounts of biogenic volatile organic compounds, such as isoprene and terpenes, are released to the atmosphere from terrestrial vegetation or anthropogenic sources. Oxidation of the biogenic volatile organic compounds leads to the formation of ozone, free radical containing particles and secondary 
organic aerosols, which require detailed study in order to better, understand the associated effects on health and climate. To pursue this research, Ghosh has developed the instrumental capability to perform Raman spectroscopy on acoustically levitated terpene droplets in a controlled gaseous environment. Acoustic (ultrasonic) levitation combined with Raman spectroscopy of the $\mathrm{C}=\mathrm{C}$ stretching band at $1662 \mathrm{~cm}^{-1}$ allowed contactless monitoring of evaporation kinetics as a function of time.

Following the presentation by Ghosh, Brian Gullett (U.S. EPA, USA) discussed a new approach to estimate the environmental impacts of grass and forest fires. Unmanned aerial systems equipped with remotely controlled miniaturized sensors and samplers for the measurement of $\mathrm{CO}$ and $\mathrm{CO}_{2}$, particulate matter, semi-volatile and volatile organics and light-absorbing carbon have been developed and demonstrated. Preliminary data from the monitoring of agricultural and forest fires were also presented. Gullett stated that the system is intended to characterize air pollutant levels, determine source pollutant strength, identify water pollutant issues and provide real-time data on environmental accidents whilst minimizing human exposure and deployment costs.

Donald Lucas (Lawrence Berkeley National Laboratory, USA) presented his research on the development of a sensitive and selective method for the measurement of mercury in ambient air by localized surface plasmon resonance. The method is also suitable for flue gases even in harsh environments because there is no interference from $\mathrm{SO}_{2}, \mathrm{NOx}, \mathrm{CO}_{2}$ and water. Lucas listed further advantages, including no requirement for an inert carrier gas and sensitivity that is compatible with ambient air applications. The method is based on surface plasmon resonance using a sub-monolayer film of $5 \mathrm{~nm}$ gold spheres and a novel optoelectronic system that is capable of measuring sub-pg masses of adsorbed mercury.

The analysis of complex aerosols from the heating of biological materials requires advanced analytical capability to characterize molecular patterns. Christopher Rüger (University of Rostock, Germany) presented a method based on Fourier transform ion cyclotron resonance mass spectroscopy equipped with an atmospheric pressure chemical ionization source. Evolved gas analysis using high-resolution mass spectrometry allows the time-resolved molecular characterization of thermally induced processes in complex materials or mixtures, such as biomass or crude oil, which can be very useful in the regulation of biomass pyrolysis processes. An example in which different lignocellulosic biomasses were pyrolyzed showed patterns that were characteristic of material origin (Rüger et al. 2015).

\section{Flame retardants - past, present and future}

The session was opened by Åke Bergman (Swedish Toxicology Sciences Research Center, Sweden). Bergman summarised the history of chemical flame retardant usage, driven by the increase in use of flammable polymers. In the 1970s research into polybrominated chemicals, including biphenyls, diphenyl ethers and other halogenated hydrocarbons, raised concerns about their potential health effects and their increasing presence in the environment. As compounds of high concern were removed from commercial use others replaced them, including chlorinated substances. The number of commercial flame retardants is currently estimated to be 50 brominated and 20 chlorinated substances, including established, novel and potential flame retardants, even though all of the chemicals regulated by the Stockholm Convention are halogenated organic compounds. Phosphate containing flame retardants, which are increasingly scrutinized because of their established or suspected toxicity, have been detected in the environment and in animals and are another widely used class of chemicals. In addition to the flame retardant chemicals themselves, there is concern about flame retardants in waste materials and especially in electronic devices. Where the disposal of electronic waste is poorly controlled, severe human and environmental contamination has been documented. Of particular concern is the uncontrolled burning of materials containing halogens, from which a wide range of toxic combustion byproducts can be formed, including halogenated dibenzo- $p$-dioxins and dibenzofurans. Bergman concluded with examples in which the use of recycled plastics has resulted in the incorporation of flame retardants in other consumer products, including kitchen utensils.

As the only industrial presenter at the Congress, Ralph Nussbaum (IKEA of Sweden AB, Sweden) discussed the topic of flame retardants from the industry perspective. Nussbaum addressed some of the issues regarding how a major furniture and furnishings retailer manages its procedures for working with chemicals in general, and in particular for flame retardants. IKEA seeks to minimize health and environmental hazards for their customers, their staff and the environment, including during the manufacture and disposal of products. IKEA products must comply with fire safety regulations which can require the use of flame retardants in products, especially in the UK and US markets. IKEA is participating in the development of improved technologies for upholstered furniture, such as the inclusion of fire resistant interliners, other fire resistant barriers and fibers with inherent flame-retardant properties, which can be implemented without the use of chemical flame retardants.

Donald Lucas (Lawrence Berkeley National Laboratory, USA) described how basic research on combustion, health effects, exposure pathways, life-cycle analysis and practical fire engineering can provide a basis for regulating the use of toxic or potentially toxic flame retardants. However, in the real world, economic, legal and political factors also affect the decision making process. Academic research scientists can provide both the basic research needed as well as providing independent 
input into regulatory and legal decision making activities. Examples where such input has had an effect include amendment of the California furniture regulation (TB-117-2013) to allow furniture foam without the use of flame retardants, revisions to building insulation standards, building codes and electronic codes (Babrauskas et al. 2012).

Anna Stec (University of Central Lancashire, UK) presented research into the effects of brominated and phosphonate flame retardants affect fire toxicity. $\mathrm{CO}$ and $\mathrm{HCN}$, the major asphyxiants in fires, were quantified from controlled burning conditions using standard industry formulations of various flame retardants. For example, $\mathrm{CO}$ yields were higher in fire scenarios where chlorinated flame retardants are present, and melamine phosphorus systems produce lower levels than a antimonybromine mixture. Phosphorous containing flame retardants are effective in suppressing ignition at lower temperatures early in the fire process where both $\mathrm{CO}$ and $\mathrm{HCN}$ form, but once the fire develops and the temperature increases these compounds minimize the potential increase in fire toxicity. Stec emphasized the need to understand the mechanisms of formation and destruction of the compounds involved in flame toxicity to avoid the development of new formulations that could increase the toxicity of larger fires, which are normally associated with deaths and injuries from toxic gas inhalation.

Anam Saeed (Murdoch University, Australia) continued the session by presenting results of research on the formation of byproducts from the gas-phase thermal decomposition of pure tetrabromobisphenol A, the most widely deployed brominated flame retardant. Bench scale flow reactor experiments in the 300 to $800{ }^{\circ} \mathrm{C}$ range were performed in a nitrogen atmosphere and with a 2 second residence time. In agreement with literature studies on the decomposition of condensed tetrabromobisphenol A and tetrabromobisphenol A-containing polymers, the majority of the bromine was found to evolve as HBr. Brominated phenols, especially 2,6-dibromophenol and 2,4,6-tribromophenol, were also formed in significant quantities. Saeed demonstrated that, in comparison with previous studies, the major reaction pathways in the gas phase are different than those for molten tetrabromobisphenol A.

The session was concluded by Staffan Lundstedt (Umeå University, Sweden) who discussed the chemical conversion of BFRs to PBDDs and PBDFs during production, use, recycling and destruction of flame retarded materials and demonstrated that conversion may lead to significant emissions of PBDDs and PBDFs. Data were presented on the concentrations and profiles of brominated dioxins and furans in plastics from TV and computer casings, as well as on the emissions during heating of the plastics at different temperatures and conditions, which ranged from laboratory experiments and semi-controlled pilot-scale experiments to uncontrolled accidental fires. Lundstedt's data revealed that large proportions of PBDDs and PBDFs were emitted when PBDE-containing material was heated or burned. In some cases the PBDD and PBDF emissions exceeded the PBDE emissions and the emitted PBDDs and PBDFs were also found to be persistent in the environment.

\section{Health effects of solid biomass combustion emissions}

The session keynote speaker Torben Sigsgaard (Aarhus University, Denmark) addressed the topics of biomass combustion, air pollution and health effects. It has been demonstrated that exposure to airborne biomass particles is associated with increased frequency of respiratory infections, cardiovascular and respiratory mortality and associated hospital admissions. The reduction in use of biomass combustion for heating has resulted in beneficial population health effects but currently it is not possible to predict the difference in health effect from exposure to biomass smoke and from exposure to other particulates in outdoor air. Consequently Sigsgaard concluded that exposure to biomass particulate should be considered as hazardous to cardio-respiratory health effects as exposure to any other particulate matter component of air pollution and, in order to protect the health of the population, Sigsgaard argued that emissions from the combustion of biomass should be minimised as far as possible.

Next speaker on the list, Raimo Salonen (National Institute for Health and Welfare, Finland) reported the results of a longterm study of exposure to wood smoke and cardiorespiratory mortality in the Helsinki Metropolitan Area. In Finland, residential heating with wood has been estimated to constitute $40 \%$ of total particulate matter $(2.5 \mu \mathrm{m})$ emissions, $55 \%$ of black carbon emissions, $30 \%$ of non-methane volatile organic compound emissions, $80 \%$ of carcinogenic PAH emissions, and $25 \%$ of carbon monoxide emissions. In the Helsinki Metropolitan Area, year-long air quality monitoring campaigns in residential areas favoring the use of wood for heating have confirmed significant air quality problems. In order to investigate the relative risks of disease mortality, a cohort study of 92,355 people in this area was conducted using registry data on person-years and disease mortality between 1981 and 2005. Salonen concluded that among the original population of 18,500 in the highest and second-highest exposure categories, the current risk estimates would result in about 500 premature cardiovascular and respiratory deaths during the investigated 25 -year period.

Ronald Wyzga (Electric Power Research Institute, USA) raised the question of the correct metric for organic particulate matter in studies of air pollution health effects. To answer this question, he described the complexity of estimating relationships between individual air pollutants and specific health effects. For instance, in 24 out of 28 epidemiological studies that considered cardiovascular responses, a significant association was established between exposure to carbon-containing particles 
and adverse outcomes, while for respiratory outcomes an association was found in 15 out of 26 studies. The complexity was increased by the very large number of organic compounds and the use of broad identifiers such as black, elemental and organic carbon, which do not allow adequate discrimination between all of the individual components. Since some organic substances have been more highly associated with health effects than others, there is a risk of underestimation of the relationship between health and exposure to organic particulate matter as the broader identifiers include numerous potentially innocuous organic compounds.

Jonathan Fagerström (Umeå University, Sweden) discussed the potential to reduce particulate emissions from biomass combustion using ash chemistry. Fagerström began by referring to the potential expansion of bioenergy from the current figure of $50 \mathrm{EJ}$ to a target figure of $160 \mathrm{EJ}$ by 2050 estimated by the International Energy Agency, which might present a significant increase in harmful emissions. In general, emissions from the combustion of biofuels have been reduced by secondary precleaning and post-cleaning measures. However, Fagerström focused on primary "in-process" measures using the time resolved release of potassium to reduce the formation of fine particles by aggregating particulates into residual bottom/boiler ash for easy removal through ash feeding systems. Both experimental and simulation methods were applied to study potassium-related chemistry during fuel conversion to control fine particulate emissions.

The last speaker of the session, Ala Muala (Umeå University, Sweden) discussed the effects of experimental exposure to wood smoke upon health in human subjects. Negative health effects such as mortality and morbidity have been associated with indoor exposure to wood smoke. However, the mechanisms behind these adverse health effects are poorly understood. Therefore, a randomized, double-blind cross-over study design was applied to the exposure of 14 healthy subjects to filtered air or sooty wood smoke and to investigate airway inflammatory responses. Lung lavage fluids and bronchial mucosal biopsies were collected by bronchoscopy sampling protocols after exposure. The results of the study indicated that exposure to wood smoke caused a significant increase in bronchial epithelial and submucosal CD3+ lymphocytes together with an increase in mucosal mast cells. Further examination also revealed a significant increase in CD8+ lymphocytes within the epithelium but unexpectedly there were no indications of neutrophilic airway response or recruitment of alveolar macrophages. Muala concluded that further research is needed to clarify the events in and mechanisms of the adverse health effects elicited by exposure to wood smoke.

\section{Concluding remarks and recommendations}

The $14^{\text {th }}$ International Congress on Combustion By-Products and Their Health Effects was a successful conference attended by almost 100 delegates from all over the world. A wide variety of scientific topics was covered in high-quality presentations. Based on the presented research, several emerging issues were identified for which we make the following statements and recommendations.

- More efficient and environmentally sound strategies are needed to manage the rapid increase in waste electrical and electronic equipment for disposal. This topic featured in several sessions and has generated unanimous concern. Thermal treatment of electronic waste generates PBDDs and PBDFs and may result in high emissions of these hazardous and trans-boundary pollutants. A related issue is the current export of high volumes of electronic waste to developing countries. The responsibility for safe and sustainable (pre)treatment, incineration and disposal of waste residues should remain with the countries generating the waste and not be passed to countries with fewer resources for waste management.

- While previous Congresses included presentations on flame retardants, the $14^{\text {th }}$ Congress was the first to dedicate a separate session to flame retardants. There is a strong consensus that the occurrence, use, and monitoring of flame retardants must be reviewed. Both legislation and fire safety testing procedures require re-evaluation because flame retardants and their combustion by-products are considered to be hazardous to human health. PBDDs and PBDFs, which can form during disposal of fire-retardant treated materials and in accidental fires from furniture and/or construction material containing brominated flame retardants, pose a potential health hazard to firefighters, construction workers and the environment.

- There is a broad consensus that exposure to particulate matter is correlated with increased cardiac and respiratory morbidity and mortality. The proposed increases in use of renewable bio-energy sources and novel materials, such as nanoparticles, present potential human health and environmental exposure risks that must be addressed. Research in these fields is currently limited, but during this Congress several studies on the topic were put forward, for example, mitochondrial DNA used as a marker for environmental stressors in early life, quantitative structure-activity re- 
lationships, human exposure studies under controlled conditions and molecular dynamics simulation.

- Another emerging concern is that biological responses to exposure are not adequately represented by single-cell based assays. For example, airway epithelial cells are injured in response to inhalation exposures and the injured cells strongly influence the function of other cells, including immune cells. Such cellular communication results in altered airway repair mechanisms and reduces the capacity to respond to other insults, such as respiratory pathogens, resulting in increased morbidity and mortality following exposure. There is thus a need to understand not only the nature and source of exposure but also the complexity of health and environmental impacts and to utilize this information to prevent adverse effects resulting from exposure to particulate matter.

- It is not possible at present to predict the difference in health outcomes from exposure to biomass smoke and to other particulates in outdoor air. Therefore, biomass particles should be considered to be equally hazardous to cardiorespiratory health as other particulate matter components. In order to assess the potentially different health impacts of particulates from biomass combustion and fossil fuel combustion, outdoor air pollution monitoring networks should enable the attribution of source contributions. In addition, more detailed knowledge is required about different particle types and their properties, and the relationship between these and their effects on health and climate. The application of new measurement techniques in combination with dedicated multidisciplinary research efforts should create opportunities to gain novel insights into combustion aerosol formation and its effects on health and climate.

- The Congress highlighted a number of new methods for characterizing combustion emissions using advanced sampling and analytical methods. Miniaturized, light-weight and low-cost sensors will allow the development of sampling networks and aerial sampling methods to characterize pollutant sources and exposure levels. Laser, spectroscopic, and optoelectronic methods allow enhanced monitoring of active species in combustion systems, diagnosis of respiratory diseases, analysis of mercury in ambient air, and characterization of droplet and gas reactions.

- Although not a major conclusion from the Congress, there is a need for further research into the alarming use of copper chloride salts to reduce soot in domestic stoves because these have been shown to increase the emissions of PCDDs and PCDFs significantly. The widespread use of these chemical chimney sweepers would result in a dramatic increase in uncontrolled PCDD and PCDF emissions from incineration.

Collectively, the findings presented at this Congress provide encouragement for further research on combustion and health with an emerging focus on bio-based energy sources and other novel sources of air pollution.

The $15^{\text {th }}$ International Congress on Combustion By-Products and Their Health Effects will be hosted by Prof. Wonnam Lee and Sunho Park and will take place in Seoul Korea in June, 2017.

\section{AUTHOR INFORMATION}

\section{Corresponding Author}

* Stina Jansson, stina.jansson@umu.se

\section{Author Contributions}

The manuscript was written from the contributions of all authors, who have given approval to the final version of the manuscript.

\section{Funding Sources}

The author(s) received no financial support for the authorship, and/or publication of this article.

The $14^{\text {th }}$ Combustion By-Products and Their Health Effects Congress was supported by funds from National Institutes of Environmental Health Sciences to SC, and the Swedish Research Council for Environment, Agricultural Sciences and Spatial Planning - Formas (219-2014-291) to SJ, CB, MLN, LL and EW. 


\section{Notes}

The contents of this article is solely the responsibility of the authors and do not necessarily represent the official views of $\mathrm{NIH}$ or the International Congress on Combustion By-Products and Their Health Effects.

The views expressed in this paper are those of the authors and do not necessarily reflect the views or policies of the U.S. Environmental Protection Agency.

\section{ACKNOWLEDGMENTS}

The authors would like to acknowledge the sponsors of the conference for their support: Agilent technologies, Bio4Energy, Cooper Environmental, County Council of Västerbotten, Dekati, ExIS, Louisiana State University, NIEHS Superfund Research Program, SP Processum, Swedish Metabolomics Centre, The Swedish Research Council Formas, Tillquist, Umeå Energi, Umeå Municipality, and Umeå University.

Figure 1 graphic templates designed by freepik.com and used under CC license.

\section{REFERENCES}

Aurell J, Gullett BK (2013): Emission Factors from Aerial and Ground Measurements of Field and Laboratory Forest Burns in the Southeastern US: PM2.5, Black and Brown Carbon, VOC, and PCDD/PCDF. Environmental Science \& Technology 47, 8443-8452

Babrauskas V, Lucas D, Eisenberg D, Singla V, Dedeo M, Blum A (2012): Flame retardants in building insulation: a case for re-evaluating building codes. Building Research \& Information 40, 738755

Benavente V, Fullana A (2015): Torrefaction of olive mill waste. Biomass and Bioenergy 73, 186-194

Conesa JA, Egea S, Moltó J, Ortuño N, Font R (2013): Decomposition of two types of electric wires considering the effect of the metal in the production of pollutants. Chemosphere 91, 118-123

Dellinger B, D'Alessio A, D'Anna A, Ciajolo A, Gullett B, Henry H, Keener M, Lighty J, Lomnicki S, Lucas D, Oberdörster G, Pitea D, Suk W, Sarofim A, Smith KR, Stoeger T, Tolbert P, Wyzga R, Zimmermann R (2008): Report: Combustion Byproducts and Their Health Effects: Summary of the 10th International Congress. Environmental Engineering Science 25, 1107-1114

Domínguez JC, Oliet M, Alonso MV, Gilarranz MA, Rodríguez F (2008): Thermal stability and pyrolysis kinetics of organosolv lignins obtained from Eucalyptus globulus. Industrial Crops and Products 27, 150-156

Edo M, Aracil I, Font R, Anzano M, Fullana A, Collina E (2013): Viability study of automobile shredder residue as fuel. Journal of Hazardous Materials 260, 819-824

Garrido MA, Font R (2015): Pyrolysis and combustion study of flexible polyurethane foam. Journal of Analytical and Applied Pyrolysis 113, 202-215

Hung PC, Lo WC, Chi KH, Chang SH, Chang MB (2011): Reduction of dioxin emission by a multilayer reactor with bead-shaped activated carbon in simulated gas stream and real flue gas of a sinter plant. Chemosphere 82, 72-77

Hung PC, Chang SH, Lin SH, Buekens A, Chang MB (2014): Pilot Tests on the Catalytic Filtration of Dioxins. Environmental Science \& Technology 48, 3995-4001

Jakab E, Faix O, Till F, Székely T (1995): Thermogravimetry/mass spectrometry study of six lignins within the scope of an international round robin test. Journal of Analytical and Applied Pyrolysis $35,167-179$

Lee GI, Saravia J, You D, Shrestha B, Jaligama S, Hebert VY, Dugas TR, Cormier SA (2014): Exposure to combustion generated environmentally persistent free radicals enhances severity of influenza virus infection. Particle and Fibre Toxicology 11, 57

Lomnicki S, Gullett B, Stöger T, Kennedy I, Diaz J, Dugas TR, Varner K, Carlin D, Dellinger B, Cormier SA (2014): Combustion By-Products and their Health Effects - Combustion Engineering and Global Health in the 21(st) Century: Issues and Challenges. International journal of toxicology 33, 3-13 
Moreno AI, Font R (2015): Pyrolysis of furniture wood waste: Decomposition and gases evolved. Journal of Analytical and Applied Pyrolysis 113, 464-473

Ortuño N, Conesa JA, Moltó J, Font R (2014): Pollutant emissions during pyrolysis and combustion of waste printed circuit boards, before and after metal removal. Science of The Total Environment 499, 27-35

Rüger CP, Miersch T, Schwemer T, Sklorz M, Zimmermann R (2015): Hyphenation of Thermal Analysis to Ultrahigh-Resolution Mass Spectrometry (Fourier Transform Ion Cyclotron Resonance Mass Spectrometry) Using Atmospheric Pressure Chemical Ionization For Studying Composition and Thermal Degradation of Complex Materials. Analytical Chemistry 87, 64936499

Sciences NIoEH (2015): Superfund Research Program. National Institute of Environmental Health Sciences

U.S. Department of Health and Human Services NIoH, National Institute of Environmental Health Sciences (2012): National Institute of Environmental Health Sciences Strategic Plan 2012-2017

Van Caneghem J, Block C, Vandecasteele C (2014): Destruction and formation of dioxin-like PCBs in dedicated full scale waste incinerators. Chemosphere 94, 42-47

Van Caneghem J, Vandecasteele C (2014): Characterisation of polycyclic aromatic hydrocarbons in flue gas and residues of a full scale fluidized bed combustor combusting non-hazardous industrial waste. Waste Management 34, 2407-2413

Vandini S, Corvaglia L, Alessandroni R, Aquilano G, Marsico C, Spinelli M, Lanari M, Faldella G (2013): Respiratory syncytial virus infection in infants and correlation with meteorological factors and air pollutants. Italian Journal of Pediatrics 39, 1-1

Zhang MM, Buekens A, Jiang XG, Li XD (2015): Dioxins and polyvinylchloride in combustion and fires. Waste Management \& Research 33, 630-643 